\title{
"Sem ilustração": a incapacidade das populações rurais na profilaxia rural do Paraná (1916-1921)
}

\section{Beatriz Anselmo Olinto*}

\begin{abstract}
Resumo: No presente trabalho, a análise da atuação da Comissão de Profilaxia Rural no Paraná (1916-1919), é o ponto de partida para a reflexão sobre diferentes processos de deterioração identitárias das populações rurais daquele estado no período de 1916 a 1921. Em meio a projetos sanitários, colonizações, resistências, miséria, falta de recursos e parcerias, além da eclosão da pandemia de Gripe Espanhola em 1918, a Comissão elaborou um extenso relatório sobre suas atividades. Com base nesses dados e dialogando com outros documentos do período, busca-se perceber como foram articuladas e constantemente apropriadas concepções a respeito das populações do Brasil em horizontes de incapacidade, tanto civilizatória quanto de gestão autônoma de suas vidas. Também são problematizadas quais expectativas de futuro, classificações de grupo e intervenções, estatais ou não, foram legitimadas por esses discursos.
\end{abstract}

Palavras-chave: Historia rural; Identificações; Doenças.

Abstract: In this study the analysis of the actions of the Commission of Rural Prophylaxis in Paraná (1916-1919), is the starting point for thinking about different processes of deterioration of the rural identity in this state in the period 1916 to 1921. In the midst of health projects, colonization, resistance, poverty, lack of resources, partnerships and the outbreak of the Spanish Flu pandemic in 1918, the Comission prepared an extensive report on their activities. Based on these data and dialogue with other documents of the period, we seek to understand how they were constantly articulated and appropriate conceptions about the population in horizons of disability for the civilization and autonomous management of their lives. Which are also problematized the future expectations, group interventions, for the state or not, were legitimized by these discourses.

Keywords: Rural history; Identity; Diseases.

\section{INTRODUÇÃO}

Toda a gente é mais ou menos infensa a submeter-se a um tratamento médico sério, sobretudo quando a doença não o fez sofrer muito, e o povo, a classe baixa, sobretudo o sertanejo sem educação e sem ilustração, é ainda mais difícil de se deixar convencer da necessidade de certas medidas terapêuticas e higiênicas. ${ }^{1}$

No presente trabalho, a análise da atuação da Comissão de Profilaxia Rural no Paraná (1916-1919), chefiada pelo médico Heráclides de Souza Araújo e autor da citação acima, é o ponto de partida para a reflexão sobre diferentes processos de deterioração identitária das populações rurais daquele Estado no período de 1916 a 1921 . Em meio a

\footnotetext{
* Professora associada da Universidade Estadual do Centro-Oeste e professora do programa de pós-graduação em História na mesma instituição.

${ }^{1}$ SOUZA ARAUJO, Heráclides Cesar de. A Prophylaxia Rural no Estado do Paraná: Esboço de Geografia médica. Curitiba: [s.n.], 1919, p. 130.
} 
projetos sanitários, colonizações, resistências, miséria, falta de recursos e parcerias, além da eclosão da pandemia de Gripe Espanhola em 1918, a Comissão elaborou um extenso relatório sobre suas atividades, bem como construiu quadros de Geografia Médica sobre as doenças, o território e as populações atendidas. Com base nesses dados e dialogando com outros relatórios da viagem e mensagens do governador no período, busca-se perceber como foram articuladas e constantemente apropriadas concepções a respeito das populações do Brasil em horizontes de incapacidade, tanto civilizatória quanto de gestão autônoma de suas vidas. Também são problematizadas quais expectativas de futuro, classificações de grupo e intervenções, estatais ou não, foram legitimadas por esses discursos.

A hipótese aqui levantada é que a noção de heteronomia auxilia a compreensão dos diagnósticos científicos elaborados, nas primeiras décadas do século $\mathrm{XX}$, por diferentes parcelas da intelectualidade nacional. Neles construíram-se regiões e identidades de grupo como formadores do que era então compreendido como o rural neste país. Os discursos podiam ser diversos, porém apresentam permanências de deslegitimação de pessoas como sujeitos autônomos e, também, deslegitimam seus saberes, hábitos e posses sobre a terra.

Para prosseguir nesse intento o primeiro passo é definir o que se entende por heteronomia e autonomia. Aqui, acompanha-se a definição de Kant, na qual a autonomia é "não escolher senão de modo a que as máximas da escolha estejam incluídas simultaneamente, no querer mesmo como lei universal." ${ }^{2}$ Assim, a autonomia deriva da noção de esclarecimento (ilustração), definida por esse filósofo. Pois que, para Kant, esclarecer era sair da minoridade, da tutela de outrem, era o uso livre da razão por si e a conseqüente responsabilidade por isso, nas palavras do autor: "A menoridade é a incapacidade de fazer uso de seu entendimento sem a direção de outro indivíduo." 3

Em oposição ao uso autônomo da razão e ao seu imperativo categórico, é que se compõem o conceito de heteronomia. Nele encontra-se uma forma de sujeição a uma lei exterior ou quaisquer outras determinações que não pertençam ao âmbito da legislação estabelecida pela consciência moral de maneira livre e autônoma, nas quais "não é a vontade que então da à lei a si mesma, mas é sim o objeto que dá a lei à vontade pela sua relação com ela" ${ }^{4}$. A heteronomia então seria uma menoridade diante da vontade de outrem, de um interesse pessoal ou passional.

A proposta aqui é compreender essa diferenciação como parte integrante da resposta a pergunta "O que é o esclarecimento?" em Kant. Conseqüentemente, esclarecer seria uma saída, uma solução. Michel Foucault também analisou o mesmo texto e destacou que o sentido do esclarecimento seria ao mesmo tempo um processo e uma tarefa, já que para Kant: “o próprio homem é responsável por seu estado de menoridade. É preciso

\footnotetext{
${ }^{2}$ KANT, I. Fundamentação da metafísica dos costumes. Lisboa: Edições 70, 2005 (p. 85, BA 87)

${ }^{3}$ KANT, I. O que é Esclarecimento? Disponível em <www.ateus.net/artigos/ensaios>, Acesso em: 12. dez.2010.

${ }^{4}$ KANT, I. Fundamentação da metafísica dos costumes. Op. Cit. (p. 86-87, BA 88-89).
} 
conceber então que ele não poderá sair dele a não ser por uma mudança que ele próprio operará em si mesmo". Uma saída autônoma. ${ }^{5}$

Então, apesar da autonomia ser a base para o esclarecimento, esse último, enquanto paradigma de conhecimento acabou delegando os imperativos ao seu próprio fundo social. Assim, "a sociedade burguesa que se desenvolveu no século XVIII entendia-se como um mundo novo: reclamava intelectualmente o mundo inteiro e negava o mundo antigo. Cresceu a partir do espaço político europeu e, na medida em que se desligava dele, desenvolveu uma filosofia do progresso que correspondia a esse processo. 0 sujeito desta filosofia era a humanidade inteira que, unificada e pacificada pelo centro europeu, deveria ser conduzida em direção a um futuro melhor" ${ }^{6}$

Esse movimento desenvolveu-se, durante os séculos XIX e XX no ocidente, por uma razão lluminista composta como força constituidora do novo, como razão instrumental que age no presente para superar o passado e construir um futuro melhor. Essa reflexão é fundamental na crítica contemporânea à dialética inerente ao esclarecimento. Construindo um paradigma de conhecimento no qual o conhecer é dominar e transformar o outro.

Essas críticas são aqui pertinentes pois que se busca incluir o projeto de Profilaxia Rural no Paraná em horizontes mais amplos de reflexão, a saber a formação do conhecimento e a manipulação da diferença na epistemé moderna. Pois que, se o projeto de Profilaxia visava criar sujeitos higiênicos em corpos dóceis, esse processo de encontro entre saberes científicos e os viventes do campo se dava através de uma postura de tutela do outro pelo conhecimento e conhecedor autorizado pela ciência. As mudanças propostas por parte da Profilaxia para as populações rurais do país à época deste estudo não foram pensadas como mudanças destas pessoas por si mesmo, ou melhor, mudanças produzidas por vontades autônomas (e imperativos universais), mas sim como objetos para os interesses e determinações nacionais de então. A política nacional era biopolítica, em nome de um projeto de construção da nação sua população deveria ser salva de sua pressuposta ignorância, suas vidas avaliadas, territorializadas, classificadas e projetadas para o futuro por diferentes dispositivos, a Profilaxia Rural no Paraná foi um deles.

\section{PROFILAXIA RURAL NO PARANÁ: IDENTIFICAÇÕES, DOENÇAS E TRAGÉDIA}

Os trabalhos desenvolvidos pela Comissão de Profilaxia Rural no Paraná entre os anos de 1916 e 1919, passaram por diferentes estratégias e olhares sobre as populações rurais paranaenses. A Comissão foi chefiada pelo médico Heráclides de Souza Araujo, médico paranaense e membro do grupo de cientistas em torno de Oswaldo Cruz. Souza Araújo voltara ao Paraná em 1916, exatamente para chefiar a Comissão de Profilaxia Rural no Estado (C. P. R. Pr.). Souza Araújo, Adolpho Lutz e Olímpio da Fonseca haviam publicado o

\footnotetext{
${ }^{5}$ FOUCAULT, Michel. O que é o esclarecimento? In: FOUCAULT, M. Arqueologia das Ciências e História dos sistemas de pensamento. (Ditos e Escritos II) 2 ed. Rio de Janeiro: Forense universitária, 2005 (p. 338).

${ }^{6}$ KOSELLECK, Reinhart. Crítica e crise: uma contribuição para à patogênese do mundo burguês. Rio de Janeiro: EDUERJ/ Contraponto, 1999, p. 9-10.
} 
relatório da viagem feita pelo rio Paraná, ao início do ano 1918, naquele mesmo ano pelo Instituto Oswaldo Cruz. ${ }^{7}$ As informações colidas durante essa viagem serão utilizadas também no relatório da C.P.R.Pr.

Inicialmente, a Comissão pretendia desenvolver uma proposta profilática para a lepra. Porém, para o grupo de jovens médicos que o acompanharam na Comissão, o desafio inicial de combate à lepra logo seria ampliado para o combate às diversas verminoses disseminadas na população rural do Estado, tanto nos campos, no litoral, nas cidades e nos sertões. A Comissão realizou trabalhos de profilaxia da ancilostomose, da ascaridíase, entre outras verminoses. Além destas, também exerceu profilaxia sobre a sífilis, o impaludismo/malária, o bócio, a doença sodoku e, diante da impossibilidade de lidar com a lepra, elaborou um grande projeto de isolamento compulsório para essa doença. A Comissão também tratou de organizar e propor diversos projetos sanitários e da ampliação das pesquisas sobre as doenças atendidas.

A problemática aqui desenvolvida busca compreender como a complexidade e o caráter trágico das vivências encontradas pelos jovens médicos da Comissão expuseram as contradições entre os planos iniciais traçados pelo olhar médico, os interesses oligárquicos, os recursos disponíveis e as vivências das populações atendidas. O relatório apresenta um mundo sem consolo, compondo um palco trágico no qual: "o belo e o horrível que compõem a vida humana tornavam-se plasticamente conhecidos, em uma sabedoria maior que as palavras." ${ }^{8}$ Além disso, rastreia-se a permanência de visões sobre as populações rurais nas quais são percebidas como incapazes para a autogestão de suas vidas impondo-lhes, como caminho para o progresso, uma vivência tutelada.

Em 1919, a Comissão entregará aos governos Federal e Estadual, como também publicará, um amplo relatório dos trabalhos desenvolvidos até aquele ano. Nele, encontra-se o mapeamento do combate realizado às doenças endêmicas que, segundo o próprio decreto que regulamentava o Serviço de Profilaxia no Estado do Paraná, "dificultavam o trabalho nos campos e concorrem para a inferioridade orgânica do Homem" ${ }^{9}$ Assim, não eram todas as doenças que seriam alvo da profilaxia, mas sim as que incapacitavam ao trabalho, como a lepra, a sífilis, o impaludismo e as verminoses, essas também eram vistas como causas de uma suposta inferioridade daquele homem.

Com a criação de uma visão de caos sanitário no universo rural, uma ação ordenatória será iniciada pelo Presidente do Estado Afonso Alves de Camargo em 1916 e mantida na década de 20, quando o governador Caetano Munhoz da Rocha imporá uma política de saúde pública sistematizada em grandes instituições no Paraná. Além de manter em funcionamento os serviços de Profilaxia Rural. Se Afonso de Camargo constituiu um tripé de

\footnotetext{
${ }^{7}$ LUTZ, A., SOUZA ARAUJO, H.C, FONSECA, O. Viagem Científica pelo rio Paraná e a Asuncion com volta por Buenos Aires, Montevidéu e Rio Grande. Memórias do Instituto Oswaldo Cruz. Fascículo III, tomo X. Rio de Janeiro: Manguinhos, ano 1918, p. 104-173.

${ }^{8}$ OLINTO, B. A . Pontes e Muralhas: diferença, lepra e tragédia no Paraná no início do século XX. Guarapuava: UNICENTRO, 2007. (p. 20)

${ }^{9}$ Decreto 799/1918 In: SOUZA ARAUJO, Heráclides Cesar de. A Prophylaxia Rural no Estado do Paraná: Esboço de Geografia médica. Curitiba:[ s.n.], 1919, p. 25.
} 
atendimento baseado na Profilaxia, vacinação e hospitais, será Munhoz da Rocha que fará uma política de saúde pública monumental, simbolizada pela construção de três grandes instituições hospitalares: uma para a centralização de todos os leprosos do estado, o Leprosário São Roque; outra para atendimento aos tuberculosos, o Sanatório São Sebastião da Lapa e, finalmente, uma para doenças transmissíveis em geral, o Hospital de Isolamento Oswaldo Cruz. ${ }^{10}$

Destaca-se que a Comissão funcionará com a parceria entre o governo Federal, Estadual e a Fundação Rockefeller, esse modelo foi implantado durante a Primeira República no Brasil, a partir de 1910. Segundo Lina Faria, é a partir de então que as áreas rurais passaram a fazer parte das políticas de saúde executadas pelo governo federal, até então essas eram muito mais centradas nos portos e na capital ${ }^{11}$.

Os recursos para essa profilaxia rural vinham do governo federal (variavam entre $1 / 2$ e $1 / 3$, conforme decreto federal de 1 o de maio de 1918 e as regulamentações estaduais posteriores ${ }^{12}$ ) Assim, constitui-se um projeto de nação que pressupunha a integração do rural ao paradigma de civilização importado da Europa em um universo no qual as "visões sobre as mazelas do Brasil se davam dentro de um enquadramento dualista habitado por pares indissociáveis, tais como litoral-sertão, saúde - doença e moderno-atrasado"13

Porém, ainda acompanhando as pesquisas de Faria, as parcerias com a Fundação Rockefeller foram firmadas após o Brasil já ter "atravessado os momento iniciais de sua reforma sanitária". ${ }^{14}$ Nesse sentido, a Profilaxia Rural no Paraná foi estabelecida em um sistema elaborado a partir dos trabalhos desenvolvidos por Oswaldo Cruz e do grupo em torno de Manguinhos. Aliança entre o governo federal, o estadual e a Fundação Rockefeller ( $1 / 4$ dos recursos) é constituída com papéis bem específicos: o primeiro encarregava-se da direção, das estratégias e grande parte dos recursos, o segundo também com recursos e pessoal para apoio logístico, e a terceira atuava de forma mais localizada, no caso do Paraná com postos em Antonina e Paranaguá. Porém, a Fundação Rockefeller fornecia a troca de experiências e bolsas de estudo para a formação dos profissionais da área médica do país. ${ }^{15}$

Cabe apontar mais um fator na instituição da CPRPr, a instância municipal de administração pública, pois o relatório aponta frequentemente para a diferença de apoio recebido por parte dos governos municipais para os trabalhos da Comissão. Esses serão peça chave para a manutenção dos serviços ou não, pois para além da escassez de recursos mapeia-se também as tensões que envolviam a realização do projeto elaborado no nível federal e executado nos domínios das oligarquias locais. Em 1919, quando Souza Araujo faz

10 Ver: OLINTO, Beatriz. Pontes e Muralhas: Diferença, lepra e tragédia no Paraná. Guarapuava, PR: UNICENTRO, 2007.

${ }^{11}$ FARIA, Lina. Saúde e Política: a fundação Rockefeller e seus parceiros em São Paulo. Rio de Janeiro: Fio cruz, 2007 (p. 52).

${ }^{12}$ SOUZA- ARAUJO. Profilaxia... Op. Cit., p. 14 e 21.

${ }^{13}$ LINA, Nísia ; HOCHMAN, Gilberto. Pouca saúde e muita saúva: sanitarismo, interpretações do país e ciências sociais. In:HOCHMAN, Gilberto; ARNUS, Diego. Cuidar, controlar, curar: ensaios históricos sobre saúde e doenças na America Latina e Cariba. Rio de Janeiro: Fio cruz, 2004 (p. 496-497)

${ }^{14}$ FARIA, Lina. Saúde e Política..., op. cit., p. 55.

${ }^{15}$ Idem (p. 40) 
uma avaliação dos trabalhos realizados dirigida ao Presidente da República, a forma escolhida pelo autor é narrar e justificar primeiro as dificuldades na execução para, somente após, no desenrolar do texto apontar as realizações, assim:

O serviço da profilaxia rural ainda representa para nós uma tentativa e uma experimentação. Sua execução se nos apresenta extremamente cheia de dificuldades em virtude da grande extensão do nosso território, da quase infinita diversidade das condições locais, onde temos de operar, e, finalmente, em face da exigüidade dos nossos recursos relativamente ao vulto grandioso da empresa. ${ }^{16}$

Apesar de fazer parte da "súmula dos trabalhos realizados"17, o texto compõe um ideia de continuidade desses trabalhos, o que conseguiria em 1920 com a renovação do convênio entre estado e o governo federal ${ }^{18}$. Também passa a ideia de uma experimentação, ou seja, se por um lado traz a noção de conhecimento produzido pela experiência, por outro ameniza as expectativas quanto ao seu resultado. Função também cumprida pelo destaque dado às dificuldades encontradas, a saber, a extensão do território, as sua diversidade local e a falta de recursos. Será a partir desse quadro que o médico passará a descrever minuciosamente a atuação da Comissão no capítulo seguinte da obra, sob o título "Geografia Médica". ${ }^{19}$ A modernidade rural é apresentada como tarefa imensa para heróis incompreendidos e solitários, quase personas trágicas.

Foi no século XX que a questão da constituição de políticas de saúde para a área rural por parte do governo federal brasileiro foi elaborada. O debate em torno da possibilidade civilizatória dessas populações levou uma intelectualidade nacionalista a primeiro diagnosticar quais seriam os entraves para esse progresso e depois a lutar pela realização da reforma sanitária nos sertões. Assim, um novo projeto de nação foi elaborado e esse "só seria viável por meio da integração do sertanejo à civilização do litoral" ${ }^{20}$

Atuação da CPRPr pode ser compreendida a partir da publicação do relatório de Artur Neiva e Belisário Penna sobre a expedição médico - científica do Instituto Oswaldo Cruz ao interior do Brasil em 1916, nele o quadro composto era de um país "com uma população desconhecida, atrasada, doente, improdutiva e abandonada, e sem nenhuma identificação com a pátria." ${ }^{21}$ Logo em seguida, ao início de 1918, é criada Liga Prósaneamento do Brasil, liderada também por Penna. Some-se a isso, a intensa publicação de artigos por parte de médicos e intelectuais tanto na capital do país, quanto na capital do Estado sobre a temática, constituía-se uma visão de atraso do Brasil em relação aos países europeus e sua nova resposta. Afinal, não era mais a culpa da raça e sim das doenças, o suposto atraso civilizatório do Brasil.

\footnotetext{
${ }^{16}$ SOUZA ARAÙjO. Profilaxia Rural..., op. cit., p. 30.

${ }^{17}$ Idem, capa.

18 PARANÁ. Mensagem do Presidente do Caetano Munhoz da Rocha dirigida ao Congresso Legislativo do Estado. 01/02/1920, p. 89.

${ }^{19}$ Idem, p. 4.

${ }^{20}$ FARIA, Lina. Saúde e Política..., op. cit., p. 52.

${ }^{21}$ LIMA, N.; HOCHMAN, G. Pouca saúde e muita saúva. Op. Cit., p. 498.
} 
Essa mudança de postura é bem representada em "Jeca Tatu - a ressurreição" de Monteiro Lobato, publicado no mesmo ano de 1918. Pois que a descrição do personagem pelo autor passara de "funesto parasita da terra" em 1914, para: "O Jeca não é assim; está assim" em $1918^{22}$. A representação do caboclo não era mais de um ser quase morto em meio a uma natureza exuberante, mas sim, de alguém doente a ser salvo pela ação da medicina. ${ }^{23}$ Essa mudança na visão de Monteiro Lobato pode ser vista como um símbolo da nova problemática construída pela intelectualidade brasileira sobre as populações rurais. Se até a primeira da década do século $X X$, o povo estava condenado a uma incapacidade civilizatória pela raça, agora, ele poderia ser higienizado através do saneamento do sertão. Esse era o novo problema a ser solucionado pelo estado e pela ciência atuando em conjunto. Visão essa que será reencontrada ao final do relatório da C.P.R.Pr.:

\begin{abstract}
Combatemos também a asserção vulgar desprovida de qualquer fundamento cientifico, tão arraigada entre o povo e também os letrados, de que a anemia do nosso povo do litoral e dos campos corre por conta da má e insuficiente alimentação, a que ele se sujeita, descrevendo os nosso patrícios do interior como vitimas da inanição em meio a uma natureza rica e uma terra que dá tudo o que se quer. $O$ que acontece é o seguinte; nas zonas de alta endemicidade da ancilostomose o homem é em geral pouco produtor porque pouco trabalha, e se não trabalha mais não é instinto de preguiça e sim por que é doente ${ }^{24}$
\end{abstract}

Na passagem acima, no mesmo sentido da ressurreição do Jeca Tatu, também o homem rural do Paraná poderia ser salvo de seu suposto "pouco trabalho". Esse não era por índole e sim por anemia. Doença esta, causada por verminoses e não por subnutrição, na visão do médico. Porém, se fosse subnutrição, aí sim seria culpa do trabalhador, pois que a qualidade da terra nunca é questionada nos discursos provenientes das autoridades ligadas ao governo do Estado do Paraná. Porém, esses discursos não podem em nada ofuscar a compreensão da diversidade de posições relacionais dos grupos envolvidos. ${ }^{25} \mathrm{O}$ convênio do Governo Federal com o Estado, que possibilitava a existência da Profilaxia Rural, necessitava criar constantemente imagens de consenso para aprovar o seu orçamento ${ }^{26}$. O convênio com a Fundação Rockefeller é elogiado, entretanto o próprio Souza Araujo aponta limites do tratamento ali desenvolvido. As oligarquias locais orbitam entre apoio aos trabalhos da Comissão e o aberto boicote a eles.

\footnotetext{
${ }^{22}$ Passagens extraídas de Urupês e Problema vital de Monteiro Lobato apud NAXARA, Márcia. Estrangeiro em sua própria terra: representações do brasileiro - 1870/1920. São Paulo: FAPESP/Annablume, 1998 (p. 25 e 28). ${ }^{23}$ Idem, p. 29.

${ }^{24}$ SOUZA ARAUJO. Profilaxia... Op. cit., p. 211.

${ }^{25}$ Sobre conflito de interesses entre governos estaduais e federais para a Profilaxia Rural, ver: LINA, Nísia ; HOCHMAN, Gilberto. Pouca saúde e muita saúva: sanitarismo, interpretações do país e ciências sociais. In: HOCHMAN, Gilberto; ARNUS, Diego. Cuidar, controlar, curar: ensaios históricos sobre saúde e doenças na America Latina e Cariba. Rio de Janeiro: Fio cruz, 2004 (p. 496-497), artigo demonstra o conflito entre governo federal e seus projetos de profilaxia e as oligarquias locais a partir da constituição de 1891.

${ }^{26}$ Sobre as estratégias para a construção de um apoio no Congresso Legislativo Estadual do Paraná para investimento em saúde ver: OLINTO, Beatriz. Pontes e Muralhas: Diferença, lepra e tragédia no Paraná. Guarapuava: UNICENTRO, 2007. A autora aponta que o orçamento para a construção de um Leprosário havia sido rejeitado pelo congresso legislativo do Paraná em 1917.
} 
Todavia, através do Relatório da C.P.R.Pr., Souza Araújo, como também os demais médicos da sua equipe, narram e organizam, avaliam e classificam as suas atividades como se essas fossem a única saída para o futuro nacional. Para isso, assumem a responsabilidade por essa tarefa de conduzir o progresso, constituindo-se como sujeitos modernos. Daí também apresentarem as dificuldades encontradas, a população atendida, as doenças, os tratamentos e os resultados.

No início do Relatório, o médico já afirma que a motivação de todo o trabalho havia sido a questão da lepra, mas por vários motivos acabara ficando relegada a um segundo plano, pelo menos naquele momento. Segundo ele:

\begin{abstract}
Vários obstáculos foram aparecendo e não se fez até hoje (1919) a profilaxia da lepra, mas em compensação, a campanha contra as verminoses em todos os municípios da marinha vai dando os mais brilhantes resultados, e a campanha antipalúdica por nós iniciada e dirigida acabou com o grande espantalho e o grande ceifador da vida dos preciosos trabalhadores do sertão. ${ }^{27}$
\end{abstract}

Na passagem acima o médico aponta os vários caminhos em que os trabalhos da Comissão se subdividiram, para além do projeto inicial. O fracasso com a lepra naquele momento inicial era amenizado pela construção de uma visão atuação diante das outras doenças. Porém, os trabalhos da Comissão e de Souza Araújo devem ser analisados dentro do quadro maior de criação, pelo Governo Federal, do Serviço de Profilaxia Rural com o objetivo de "combater as endemias que assolam o interior do pais" 28 . Através desse Serviço foram fundados postos sanitários em várias cidades do interior do país. É com esse sentido que, em 1919, ainda sob o impacto da Gripe Espanhola, os serviços nacionais de saúde são reformulados ${ }^{29}$.

Souza Araújo continua a obra relatando as campanhas realizadas contra as verminoses, o trabalho conjunto com a Comissão Rockefeller ${ }^{30}$, o caos dos serviços de saúde no Paraná quando da Gripe Espanhola. O Relatório, além de ser uma fonte profícua sobre esses assuntos, apresenta as propostas do médico para o atendimento à lepra. Nelas delineia-se a sua visão sobre o isolamento. Esses indícios apontam que, entre os finais das décadas de 10 e 20, ocorreu uma mudança de perspectiva médica e política sobre a saúde das populações, demarcando uma maior atuação estatal na saúde pública. As políticas de saúde pública nesse período demonstram a ampliação do papel do estado, assumindo a responsabilidade pelo manejo das populações.

Por outro lado, percebe-se Souza Araújo como um sujeito da razão que projeta sobre o papel um vir a ser futuro para aquelas populações. Para isso os trabalhos da

\footnotetext{
${ }^{27}$ SOUZA ARAÙjO. Profilaxia Rural...., op. cit., p 12.

${ }^{28}$ Artigo 1 ㅇ do decreto 13/ 001 de 1ㅇ de maio de 1918 que criou o serviço, In: SOUZA ARAÚJO. Idem, p. 20.

${ }^{29}$ Ver: OLINTO, B. A. Uma cidade em tempo de epidemia: Rio Grande e a Gripe Espanhola. Dissertação (Mestrado em História). Florianópolis: UFSC, 1995.

${ }^{30}$ A Comissão Rockefeller, segundo ROSEN, atuava no sentido de auxiliar os países na "criação de agências de saúde nacionais e locais, incluídos os recursos humanos e materiais sobre os quais, no futuro se possam sustentar". Ver: ROSEN, George. Uma História da Saúde Pública. São Paulo: UNESP, Rio de Janeiro: HUCITEC, 1995, p. 363.
} 
Comissão eram também uma organização das gentes e das coisas em um conhecer elaborado através da classificação, do levantamento estatístico e espacialização das doenças. O médico construía em seus escritos um mundo perfectível, sua visão era de superação constante rumo ao progresso e de uma crença, até aquele momento, inabalável na ciência e no futuro.

Espacializar a distribuição de doenças é um criar de territórios para elas, possibilitando assim, o domínio desse território por um saber estratégico, sendo então um suporte para o exercício de poderes. Acompanhando Foucault, ao recorrer à geografia o discurso médico estaria se apropriando dos dois procedimentos de verdade que ali se encontram. A saber, o inquérito seria o procedimento de verdade das ciências naturais; o exame, o procedimento de vigilância das ciências humanas ${ }^{31}$. Pode-se então perceber, de que maneira a medicina ancora a sua cientificidade duplamente, nas ciências naturais e nas ciências humanas.

\section{UMA GEOGRAFIA MÉDICA: O INQUÉRITO, O EXAME E A VIGILÂNCIA}

Para compreender o horizonte conceitual da atuação médica de Souza Araújo é necessário refletir sobre a concepção de Geografia Médica. O conceito Geografia Médica é advindo do século XIX, mais especificamente da obra Ensaio de Geografia Médica de Boudin em 1843. Segundo Sandra Caponi, nessa obra o autor procurava por leis de propagação das enfermidades que fossem análogas às da distribuição das espécies vegetais. Isso é, percebendo a influência da latitude, longitude, temperatura, pressão, geologia, relevo, etc. Assim, a Geografia Médica tinha como objetivo "estudar a distribuição das doenças e conhecer as modificações que imprimem no organismo por influência do clima." 32 Desse conhecimento adviria o projetar das intervenções necessárias no ambiente com o objetivo de controle das doenças. Ideias que fundamentavam, por exemplo, a secagem de pântanos, pois que esses para Boudin seriam propícios para febre palúdicas e a peste. ${ }^{33}$

O conhecer geográfico é então apresentado como um suporte à condição de possibilidade do exercício de poderes científicos e estatais para o saneamento do ambiente e a saúde das populações. Nesse caminho o capítulo "Geografia Médica" do relatório da Comissão de Profilaxia Rural inicia com a descrição e avaliação dos trabalhos realizados por esta em Curitiba e no início do ano de 1917, o então Presidente do Estado Affonso de Camargo faz também sua avaliação da necessidade da Profilaxia e de sua atuação:

Se há serviço público que mais deva preocupar a atenção dos governantes é sem dúvida o da higiene. Em que pese a salubridade e a amenidade do nosso clima, devemo-nos acautelar contra moléstias endêmicas e epidêmicas. ${ }^{34}$

\footnotetext{
${ }^{31}$ FOUCAULT, M. Microfísica do Poder. 10 ed. Rio de Janeiro: Graal, 1979, p. 162.

${ }^{32}$ CAPONI, Sandra. Sobre La aclimatación: Boudin y La geografia médica. História, Ciência e Saúde- Manguinhos.

V.14, n. 1, p. 13- 38, jan.- mar. 2007, p. 29.

${ }^{33}$ Ver: CAPONI. Idem..., p. 29.

${ }^{34}$ PARANÁ. Mensage... 01/01/1917, p. 11.
} 
Daí a importância do trabalho da Comissão, pois naquele momento estava a percorrer "o Litoral do Estado, onde faz a geografia médica daquela região, para que, em virtude das observações feitas, possa o governo tomar as providências que elas aconselham." ${ }^{35}$ Percebe-se então a visão do conhecimento científico instrumental, na qual as informações levantadas pelo trabalho da C.P.R.Pr. seriam a origem de uma ação eficaz por parte do governo do estado na gestão da higiene pública.

Trazer o conceito de Geografia Médica para o Paraná nas primeiras décadas do século XX apresentava-se aos envolvidos como um trabalho hercúleo. Foi assim constituída toda uma hierarquia burocrática entre guardas sanitários, técnicos laboratoriais e médicos. Para cobrir esse espaço, a C.P.R.Pr. contava com uma equipe inicial interdisciplinar com dez médicos e composta por microscopistas e guardas sanitários. O pequeno número de pessoas envolvidas na Comissão aponta a importância das parcerias municipais para a realização dos trabalhos e, com a Fundação Rockefeller, para o levantamento de dados.

Abaixo se pode observar a amplitude do levantamento da Comissão, através do mapa elaborado a partir dos dados sobre a infecção por Ancilostomose no estado.

Figura 1: Mapa do Paraná na perspectiva médica da Ancilostomose

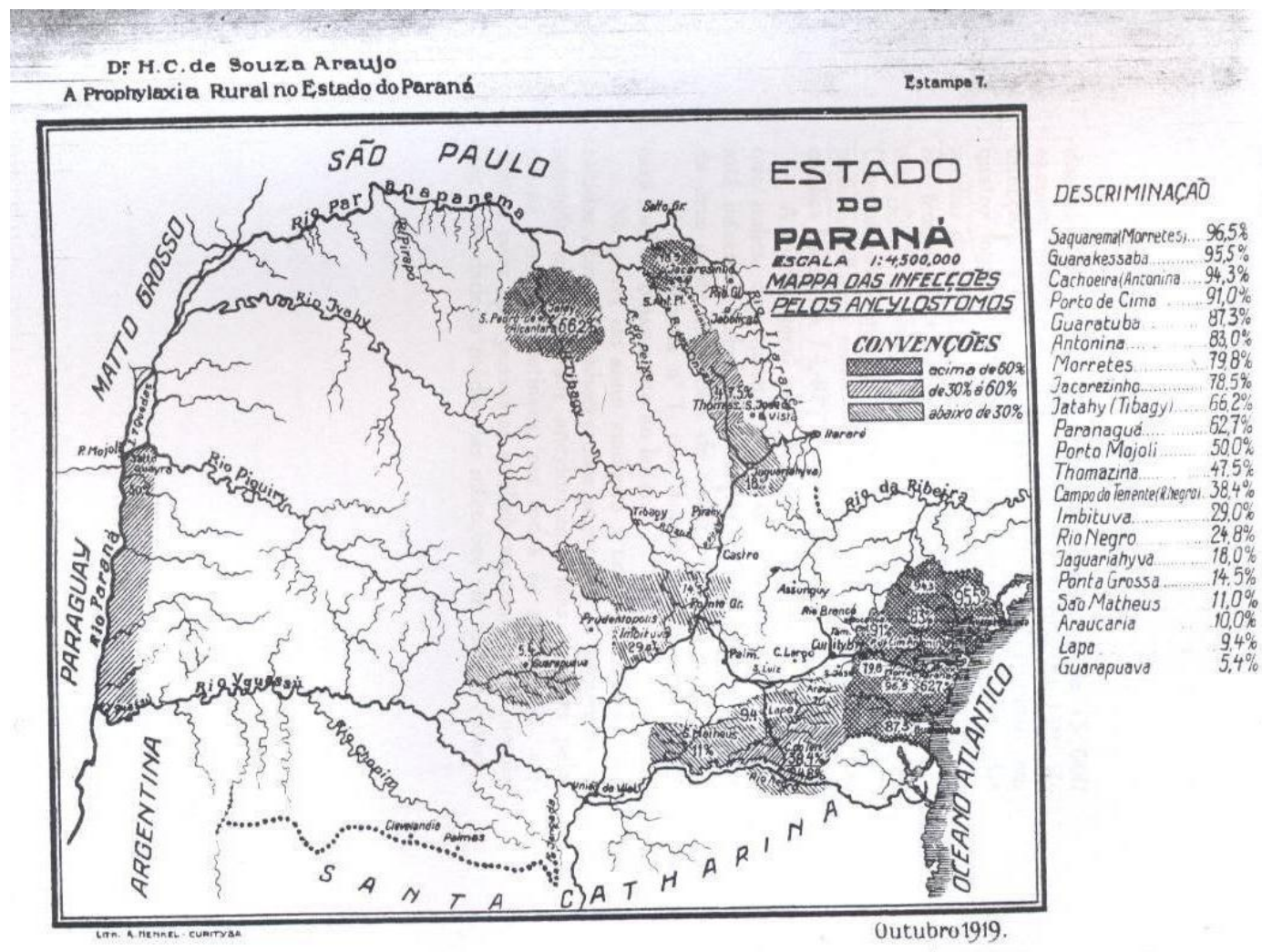

Fonte: SOUZA ARAUJO. Profilaxia. Op. Cit.

É importante destacar que essa espacialização era sempre feita a partir das normativas do Instituto Oswaldo Cruz no Rio de Janeiro, como também eram os saberes desse Instituto

\footnotetext{
${ }^{35}$ PARANÀ. Mensagem.... 01/01/1919.
} 
que instruíam todo o projeto de Profilaxia Rural no país. No Paraná as medidas adotadas pela Comissão Profilaxia Rural iniciaram pela capital do estado. Essa não escapava a percepção de rural, pelo menos no olhar projetado do Rio de Janeiro. Consequentemente, os trabalhos realizados em Curitiba iniciam, com a abertura do Posto de Profilaxia. Lá a situação apresenta-se um pouco diversa em relação as outras localidades do Paraná, pois o seu posto será central, ou seja, o local de centralização de todos os trabalhos da Comissão. Para isso o Governo Federal definiu em junho de 1919 que somente funcionariam junto ao Posto Central os serviços de vacinação e o dispensário anti-sifílico, devendo ser fechada a Policlínica dos Pobres que funcionava, até então, no mesmo prédio. ${ }^{36}$

Entretanto, pode-se compreender melhor essa instrução acompanhando o Relatório. Nele Souza Araújo informa que, após a epidemia de gripe de 1918, “[...] a população pobre desta capital continuou a procurar, para consulta de todas as doenças, o nosso posto central, acostumada que estava a ser aqui prontamente socorrida por ocasião da grande epidemia". Em consequência disso, o Ministro da Justiça e Negócios Interiores, a quem estava subordinada a Comissão, havia decidido pela extinção da tal Policlínica dos Pobres, pois "[...] a maioria destes doentes não interessava muito a questão da higiene pública, e devendo os médicos internos se preocupar mais com as pesquisas de laboratório e o dispensário anti-sifílico [...]". ${ }^{37}$

Nessa passagem, a constituição da doença como problema a ser solucionado, quase nada tem a ver com a sua existência natural e sim com as questões históricas que transformam em um dado momento, uma determinada doença, em um problema. Segundo o Relatório em questão, a população de Curitiba padecia de muitas outras moléstias e as percebiam como passiveis de tratamento médico e a ele recorriam. Mas, apesar dessa demanda, o Ministério havia decido fechar esse serviço em favor da higiene, da pesquisa e do tratamento da sífilis. Indicando que o atendimento disponível por parte de uma medicina social é definido pelos cânones da ciência e da administração pública e não por demanda.

Esse evento narrado por Souza Araujo corrobora com as interpretações recorrentes na historiografia sobre esse momento histórico, como um período no qual a intervenção buscava prioritariamente salvar o futuro nacional, em nome de um modelo de civilização ocidental moderna. As populações pobres eram percebidas como potencialmente perigosas e entraves a esse modelo. A higienização dos seus corpos e o saneamento do seu habitat seria, supostamente, o caminho para transformá-las e sujeitá-las à produtividade capitalista. A Comissão de Profilaxia apresenta-se nesse quadro como uma operação estratégica de produção de conhecimento, daí também a importância das pesquisas realizadas por seus membros, pois delas deveria decorrer a verdade científica sobre o presente que instrumentaria a intervenção estatal e possibilitaria prever e controlar o futuro.

Logo a seguir, na narrativa do próprio médico, ele informa que, após o fim da Policlínica dos Pobres no mês de junho de 1919, “[...] pudemos nos escusar da obrigação de

\footnotetext{
${ }^{36}$ SOUZA ARAUJO. Profilaxia... Op. Cit., p. 40.

${ }^{37}$ Idem (p. 50).
} 
examinar e tratar todos os doentes que procuravam o nosso serviço, mas, pelo habito de humanidade que adquire todo o médico que lida com o povo, fomos afrouxando e hoje a consulta gratuita diária no nosso serviço voltou a ser um fato." ${ }^{38} \mathrm{~A}$ vida é mais complexa que os projetos e se infiltra nas fissuras dos dispositivos.

O Dispensário Antissifilítico de Curitiba era apresentado como o arquétipo civilizacional da Comissão, lá era a central de comando da estratégia profilática, o local que abrigaria os principais laboratórios. Um espaço disciplinar privilegiado para estudar os comportamentos desviantes. Porém, as pessoas atendidas pela Policlínica dos Pobres também estavam lá. Elas eram sujeitos que sabiam resistir e manipular regras e situações que se apresentavam. Tal fato expõe os médicos a uma dimensão trágica do viver, pois a população recorria aos seus saberes, entretanto os parcos recursos dispensados à saúde não haviam sido projetados para esse tipo de atendimento. No projeto profilático rural, a população que deveria ser salva e as doenças que deveriam ser combatidas tornavam-se apenas uma projeção sobre os viventes. As máximas a serem conhecidas e atendidas eram exteriores à vontade dos envolvidos, eram máscaras, fantasmagorias científicas, apartadas da vontade e necessidade cotidiana.

Retomando a análise da opção da Comissão de Profilaxia Rural do Paraná por uma geografia médica, destaca-se que essa opção já indicava o caráter de seus procedimentos. 0 conhecer geográfico reunia em si os procedimentos do inquérito (ciência naturais) e do exame (ciências humanas). Nele a verdade constituía-se tanto por ajustamento de partes (testemunhos, provas), quanto pela vigilância (um olhar minucioso). ${ }^{39}$ Daí deter-se um pouco mais no funcionamento deste dispositivo.

O funcionamento dos serviços profiláticos iniciava com a abertura do Posto Sanitário. Esse era organizado em um prédio cedido pela prefeitura local e tinha a sua direção geral entregue a um médico diplomado. Esse último deveria residir no local e realizar os tratamentos gratuitamente. Também cabia ao médico visitar em casa os doentes que resistissem ao tratamento e convencê-los a participar, bem como proferir as conferências educativas para a população. ${ }^{40}$ Os resultados esperados dessas medidas podem ser resumidos na passagem abaixo:

\footnotetext{
Vereis que aos poucos estes indivíduos pálidos, edemaciados, barrigudos, e de olhos sem brilho, de pele cor de terra, de fisionomia sem expressão, de artérias sem sangue, de cérebros sem inteligência e de crescimento retardado, irão cada dia rareando mais e a saúde voltará aos vossos lares e com ela a alegria e a felicidade. Então levantareis as mãos para o céu e agradecereis ao Deus de vossa religião os benefícios que a ciência vos trouxe. Chegará então o dia, feliz para a nossa pátria, em que não mais serão chamados os nossos irmãos do litoral e dos campos, de indivíduos, indolentes e preguiçosos e sem inteligência. ${ }^{41}$
}

\footnotetext{
${ }^{38}$ SOUZA ARAUJO. Profilaxia... Op. cit., p. 50.

${ }^{39}$ Ver: FOUCAULT, M. A verdade e as formas jurídicas. 3 ed. Rio de Janeiro: NAU, 2003 e FOUCAULT, M. Sobre a Geografia In:FOUCALUT, M. Microfísica do Poder. 10 ed. Rio de Janeiro: Graal, 1979.

${ }^{40}$ SOUZA ARAUJO. Profilaxia... Op. Cit., p. 66.

${ }^{41}$ Idem, p. 64.
} 
A citação acima foi retirada do discurso proferido pelo médico Heráclides de Souza Araújo em 12 de dezembro de 1918, quando da inauguração do Posto Sanitário do município de Morretes. Esse discurso foi reproduzido pelo seu autor tanto no Relatório da Profilaxia Rural do Paraná, quando na Revista Paraná Médico.

O Posto Sanitário de Morretes foi o primeiro inaugurado pela Comissão Sanitária Federal para o Estado do Paraná fora da capital. O posto de Morretes já estava em pleno trabalho desde o dia 10 de outubro de 1918, porém, só foi inaugurado oficialmente, segundo as palavras do próprio médico "aproveitando a presença do Sr. Dr. Lewis Wendell Hackett, diretor no Brasil do Conselho Sanitário Internacional da Rockefeller Fundation" ${ }^{42}$, o qual estava no Paraná para firmar a parceria para a instalação de dois postos de campanha contra a ancilostomose, verminose mais abundante no litoral segundo os levantamentos da própria Comissão de Profilaxia.

A inauguração do Posto de Morretes foi adiada quando da eclosão da Gripe Espanhola, à qual se seguiu a paralisação dos trabalhos da Comissão no dia 20 de outubro de 1918, pois todos os seus membros foram desviados para o atendimento à população doente. Nas palavras de Souza Araújo: "ficou o pessoal da nossa comissão a disposição do Governo do estado para auxilio no combate a gripe." ${ }^{43}$ Mas, também a Gripe, transformou-se em dados e porcentagens de letalidade populacional ao encontrar a Comissão, como pode ser verificado abaixo:

O sistema projetado era tão eficaz que mesmo doenças não previstas acabavam por fortalecê-lo, pois que forneciam mais informações para a totalização geográfica e podiam ser alardeadas como serviços prestados, como no caso da Gripe Espanhola e da Policlínica dos Pobres.

Sobre a ordenação do Posto da profilaxia pode ser percebida a preocupação de detalhar todas as funções e hierarquizá-las no Relatório. Assim, cada Posto deveria contar com um microscopista, ressaltando uma vez mais a importância da pesquisa empírica (no caso e exame de fezes) para a construção da verdade na geografia médica. Sobre a hierarquia, essa era estruturada e projetada com minúcia, assim: “Os guardas só poderão administrar o tratamento por determinação do médico, não podendo nunca alterar a dose prescrita." Ou ainda: "qualquer sintoma diferente [...] o guarda deverá sem demora correr e dar conta do que se passa para o médico."44

Assim, o relatório sempre reitera a autoridade do médico sobre o guarda, essa necessidade de reforçar frequentemente o papel de cada categoria envolvida no projeto e deixar claros os limites da atuação dos guardas sanitários, indicia um receio do médico em relação a estes últimos. Talvez uma falta de confiança na sua subserviência à hierarquia e à autoridade científica. Talvez por serem pessoas escolhidas entre os moradores locais, mais próximos dos pacientes, proximidade reforçada por visitarem as residências e ministrarem

\footnotetext{
${ }^{42}$ SOUZA-ARAUJO. Profilaxia... Op. cit., p. 61.

43 Idem, p. 121.

${ }^{44}$ Idem, p. 71-72.
} 
os medicamentos, o que poderia acarretar um reconhecimento como uma autoridade saneadora por parte da população local. Mas são apenas hipóteses.

Figura 2: Quantificação da Gripe Espanhola



Fonte: SOUZA ARAUJO. Profilaxia.Op. cit.

Logo ao início do serviço o município em questão era dividido em zonas e cada uma delas era entregue a um guarda sanitário. O serviço do guarda baseava-se na coleta de material e tratamento. O diagnóstico e a prescrição do tratamento eram exclusividade dos médicos, porém a coleta e o ministrar dos remédios indicados para a população eram feitos pelos guardas sanitários.

Para isso toda uma série de dispositivos burocráticos é instaurada, os guardas sanitários deviam fazer a numeração, identificação de todas as casas na zona de sua responsabilidade e anotar em suas cadernetas os dados de cada morador e as doses ministradas a eles. Além disso, o guarda sanitário era encarregado de distribuir os folhetos 
informativos. E mais, ele poderia a qualquer momento perder o seu emprego: "O guarda ou qualquer outro funcionário que se apresentar freqüentemente doente, prova a sua incapacidade para os serviços da comissão e será obrigado a deixar o emprego." ${ }^{\prime 4} \mathrm{O}$ guarda e outros cargos inferiores na hierarquia profilática, aparecem como seres limítrofes entre o saber científico e o povo. Podendo cruzar uma tênue linha que parece separar os dois grupos por se apresentar doente, estigma incapacitante para a função na visão da Profilaxia.

Ao final se organiza com os dados um boletim mensal com cópias enviadas ao Ministro da Justiça, ao secretario do Interior do Estado, ao Diretor da Higiene e a imprensa. ${ }^{46}$ O essencial era produzir informações, disciplinar corpos e hierarquizar saberes; o prédio, o censo, os medicamentos e a propaganda são seus instrumentos.

Essa atuação é que constrói o esboço de Geografia Médica no Paraná apresentado no Relatório da Comissão, mas nele também são territorializadas regiões a partir de uma divisão nosológica. Apesar das doenças apresentarem-se em todos os locais analisados pela Comissão, a sua atuação deveria escolher quais seriam combatidas em cada lugar.

É nesse sentido que Curitiba é descrita sempre a partir do Dispensário Antissifilítico. Cabe destacar que o atendimento ali prestado era gratuito para meretrizes (devidamente recenseadas e identificadas) e indigentes. Também oferecia leitos para que as mulheres que não tivessem onde ficar durante o tratamento e fossem internadas. Para, assim, segundo o médico, não continuassem a disseminar ao doença por "falta de opção para sobrevivência". Todas as meretrizes eram "obrigadas a comparecer decentemente vestidas e portar-se respeitosamente, sob pena de censura.[...]" ${ }^{47}$ A profilaxia da sífilis era baseada também no recenseamento e na expedição de carteiras de identificação das prostitutas. $^{48}$

Bem diferente é a região denominada Litoral. Essa compreendia as localidades de fato litorâneas e as que ficavam entre essas e o início da Serra do Mar. Lá seria o lugar de maiores resistências do mandonismo local, segundo Souza Araujo:

É preciso confessar que a nossa ação não foi recebida com a boa vontade que era de se esperar. Diversos indivíduos de cidade e entre eles o homem de mais responsabilidade na administração municipal, procuraram impedir a execução das mais comezinhas medidas de higiene pública, tais como a construção de latrinas, etc. Uma verdadeira luta. ${ }^{49}$

O Litoral é o espaço para os chamados "refratários" à profilaxia. O médico descreve a região em situação de penúria e ausência de água potável, de esgotos e latrinas. Em Morretes, a prescrição é "persuadir refratários", a Comissão intensifica a estratégia de visitas domiciliares para o convencimento da população bem como as propagandas em panfletos e filmes. Souza Araujo organiza todo um esquadrinhar da municipalidade, exige

\footnotetext{
${ }^{45}$ Idem, p. 70.

${ }^{46}$ Idem, p. 153.

${ }^{47}$ Idem, p. 298.

${ }^{48}$ Idem, p. 285 e 308.

${ }^{49}$ Idem, p. 65.
} 
exatidão e minúcia nos relatórios, cria prêmios e penalidades. O resultado dos exames e trabalhos é por fim quantificado: 100\% infectados, 50\% com anemia, 149 latrinas construídas. Nas vizinhas Antonina e Porto de Cima, a malária e as verminoses são identificadas. Os médicos da Comissão trabalham ali com apoio da Fundação Rockefeller e diagnosticam também $100 \%$ da população infectada por verminoses. Destaca-se a inexistência de fossas em Porto de Cima e, principalmente, a alta letalidade de Gripe (57\%) em Antonina, mas essa não recebe nenhuma explicação ou formulação de hipóteses por parte da Comissão, mesmo diante da média geral de mortalidade no Paraná, apenas 1,8\%, os dados da própria Comissão. No Litoral, apesar de existirem dois portos, Antonina e Paranaguá, o relatório não problematiza a existência de sífilis.

Ainda no Litoral, agora em Paranaguá, a preocupação é a malária e também as verminoses, $100 \%$ da população diagnosticada com vermes. Nessa localidade, a parceria com a Fundação Rockefeller será descrita pelo médico: “Comprometeu-se esta (Fundação Rockefeller) a instalar um posto de campanha contra as verminoses no município de Paranaguá." ${ }^{50}$ A diferença de projetos profiláticos e os conflitos internos do campo científico na área médica são apontados pelo médico:

Nota - Em Paranaguá a comissão Rockefeller limitou-se a tratar os opilados, sem cogitar do serviço de latrinas o que nos obriga a fazer este serviço com máxima urgência, porque do contrário, terminado o tratamento, poucos meses depois de curados se reinfestarão outra vez. ${ }^{51}$

A distinção apontada é central na estratégia de Souza Araujo, não é a toa que existem punições previstas para a não construção de fossas e intimações para a construção foram distribuídas por todo o litoral ${ }^{52}$, se alguma consequência daí decorreu não se tem indícios até o momento. Porém, Souza Araujo conhecia bem os insucessos da Fundação Rockefeller e os aponta em diferentes momentos do texto ${ }^{53}$. Para o médico as falhas estavam exatamente na vigilância constante dos doentes, pois que, a Fundação Rockefeller distribuía os remédios e não fiscalizava a sua ingestão. Ao contrário, na Profilaxia Rural, um guarda sanitário passava de casa em casa ministrando a dose prescrita pelo médico, esse método era denominado de intensivo e justificado pela gravidade da situação do Litoral, pois que esse logo "tornar-se-ia inabitável" por causa das verminoses. Nas palavras do nosso narrador:

O método intensivo ou sistemático é o mais próprio para as grandes campanhas contra as verminoses intestinais e aquele que apresenta ${ }^{54}$ todos os requisitos de êxito completo. A base do método é o tratamento a domicilio de toda uma

\footnotetext{
${ }^{50}$ Idem, p. 84.

${ }^{51}$ Idem, p. 87.

52 Idem, p. 93.

53 Idem, p. 87 e 192.

${ }^{54}$ Idem, p. 100.
} 
população opilada, dirigido pessoalmente pelo médico, e freqüentemente fiscalizado pelos seus auxiliares. ${ }^{55}$

A Profilaxia Rural construiu muitos planos de intervenção, mas tinha poucos recursos a ela destinados pelos governos Federal e Estadual. A insistência de Afonso Camargo e Munhoz da Rocha em elogiarem a pessoa de Souza Araujo como ilustre, digno e perseverante $^{56}$ é inversamente proporcional ao apoio financeiro aos seus projetos. Médicos e populações abandonados pois em um palco trágico ninguém terá consolo.

Entretanto a agricultura no Paraná durante o período de 1916 a 1921 é apresentada como um sucesso pelos presidentes do estado. Afonso Alves de Camargo, em sua Mensagem ao Congresso Legislativa ano início de 1918, se refere ao ano de 1917 como: "ano decorrido foi de verdadeiros triunfos para o nosso estado no que diz respeito a sua produção agrícola." ${ }^{57}$

O referido presidente também prevê um grande futuro para o Paraná através da agricultura: "Nesse dia seremos um dos expoentes máximos da riqueza econômica do Brasil. [...] E estou seguro que esse dia não tardará desde que continuemos, sem esmorecimentos, a nossa propaganda rural, pois o abandono do campo é a única hipótese de fracasso do nosso engrandecimento futuro." ${ }^{58} \mathrm{E}$ o incremento agrícola do estado, a lisonjeira situação financeira decorrente e o elogio aos trabalhos da Profilaxia Rural se repetem ano a ano.

\section{POPULAÇÃO RURAL TUTELADA: PERMANÊNCIAS E VISAGENS}

Pode-se indicar que o trabalho da Comissão ajudou na diminuição das resistências existentes, durante a primeira década do século passado, ao investimento público vultoso na área da saúde. Tais resistências parecem ter sido dissipadas através da constituição de uma verdade médica calamitosa sobre a situação do interior do Estado, visão essa instituída a partir dos trabalhos da Comissão de Profilaxia.

Souza Araujo defendia a ação direta do médico sobre a população, o que aproximaria a "autoridade" do "povo" com a entrega dos remédios no próprio "habitat". Um método "intensivo" segundo o autor, através do recenseamento, visitação do médico e seu "uso assistido" dos medicamentos, ou seja, a sua administração pelo guarda sanitário. Só assim, com essa proximidade com essa população "refratária, o médico passaria "[...]a ter sobre eles verdadeira e direta ascendência. A ação do povo passa a ser apenas obedecer, cumprir ordens em seu benefício e deixar-se medicar." ${ }^{59}$ Como já dissera Trajano dos Reis "e não se pode cuidar da salvação pública sem ser um ditador" ${ }^{60}$.

\footnotetext{
${ }^{55}$ Idem, p. 163.

${ }^{56}$ Ver. PARANÁ. Mensagem do Presidente..., op. cit., p. 1916-1921.

57 PARANÁ. Mensagem do Presidente Afonso Alves de Camargo ao Congresso legislativo do Estado 01/02/1918 (p. 33)

${ }^{58}$ Idem, ibidem.

${ }^{59}$ SOUZA ARAUJO. Profilaxia..op. cit.., p. 130.

${ }^{60}$ Idem, p. 112.
} 
Para justificar o autoritarismo evidente das afirmações da profilaxia, são compostas visões depreciativas arquetípicas sobre as populações rurais. Nesse sentido, o Relatório apresenta, além das resistências das oligarquias locais, também formas de resistências das próprias populações rurais, apesar de lidas depreciativamente dentro de modelos arquétipos de teimoso e ignorante, respectivamente:

Cuidando carinhosamente, fazendo-se respeitar pela nobreza do seu gesto, vai o médico, pouco a pouco, se apoderando da confiança da gente dos campos, levando-a, com habilidade, ao exame e tratamento das outras doenças, que, raramente, suspeita causar-lhe dano. Porque essa gente é naturalmente impressionável, o médico não esquece os meios de que a ciência pode dispor para convencer os mais teimosos. ${ }^{61}$ (...) No dia em que se conseguir pela educação do sertanejo convencê-lo de que o maior mal que ele pode fazer a si mesmo, aos parentes e vizinhos é permitir que em redor da sua habitação, na horta e no seu pomar, continuem a espalhar fezes humanas ou defecar na superfície do solo ora aqui, ora ali, poderemos precisar o tempo necessário para a extinção da ancilostomose entre nós ${ }^{62}$

O teimoso e o ignorante são quase ingênuos, seres abandonados em sua eterna minoridade. Uma nova ordenação só poderia vir como uma salvação externa a essas criaturas sem nenhum traço de civilização. Convencidos das benesses da ciência porque são impressionáveis e, se um dia forem educados, cessarão apenas de adoecer por sua própria culpa. A Profilaxia apresenta-se como uma positividade biopolítica, única forma de incluí-los no projeto nacional seria manipulá-los e salvá-los de si mesmo.

Figura 4: Um dos modelos de construção de fossas

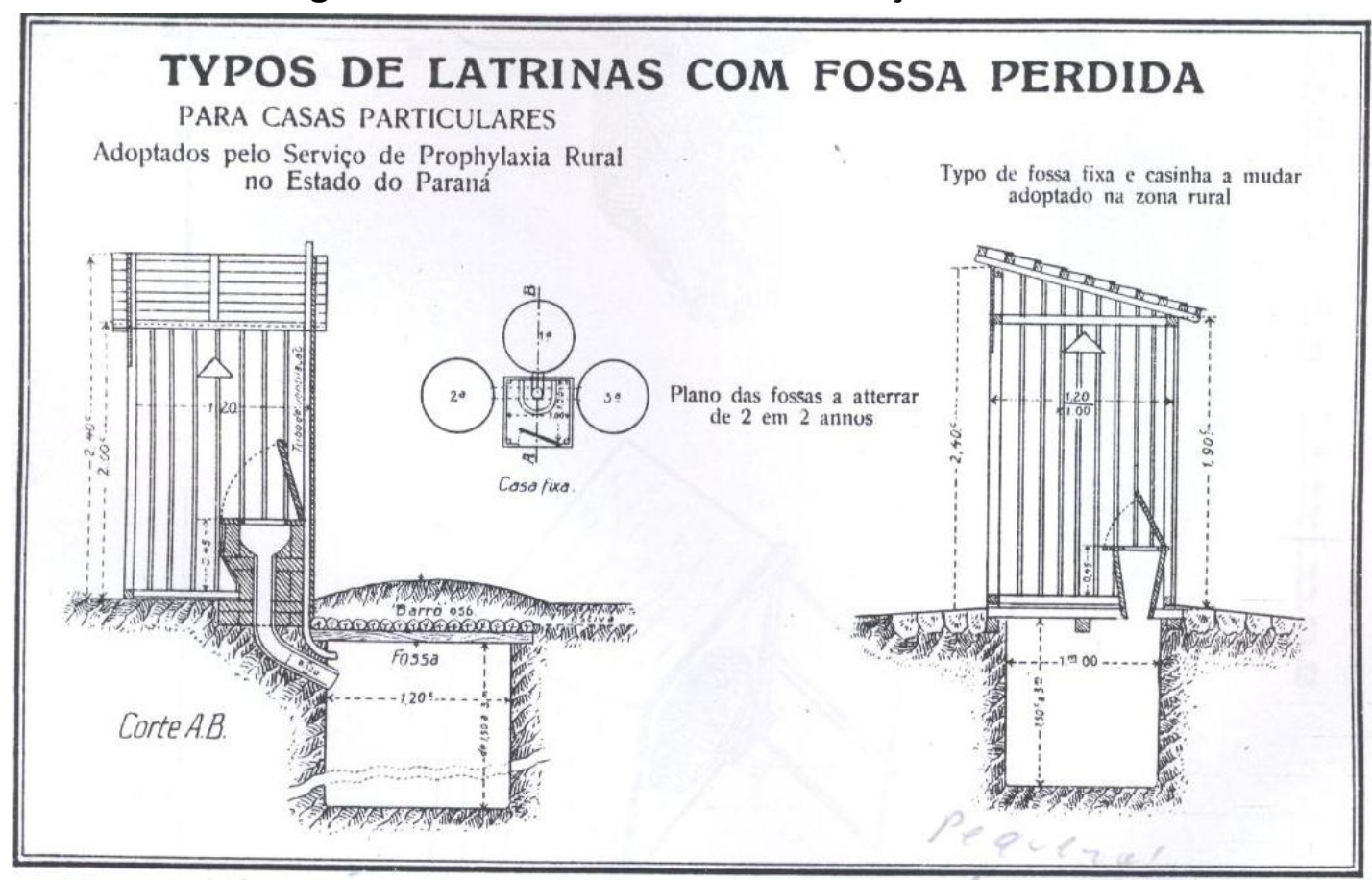

Fonte: SOUZA ARAUJO. Profilaxia...op. cit.

\footnotetext{
${ }^{61}$ Idem, p. 158.

62 Idem, p. 211.
} 
Com isso suas vidas serão expostas como vidas nuas, no sentido definido por Giorgio Agamben ${ }^{63}$, ou seja, sua hexis corporal será minuciosamente examinada e seus costumes terão valoração moral ao tornarem-se maus hábitos, pois: "Não há nenhuma zona do Estado que a gente visite, seja no litoral, seja nos campos, nos sertões ou no Baixo Paraná, em que se não encontre o povo dominado pelo mal habito de não fazer usos de latrinas." 64

O que enfim está aqui sendo gerido por essa profilaxia? Vidas olhadas por um projeto político, ou melhor, vidas nuas objetos de biopolítica. Uma vida exposta a luz de saberes a fim de transformá-la em operações reconhecíveis e previsíveis. A Profilaxia lidava com a vida compondo duplos como: civilização e barbárie, progresso e atraso, higiene e perigo, sujeito da ação e objeto de pesquisa. Duplicação integrante da ordenação das coisas e das gentes pela epistemé moderna. O ser - humano é duplicado e seu ser e estar no mundo analisado e modificado. Acompanhando Naxara: "O povo brasileiro, visto por suas elites, aproximava-se do atraso e da barbárie, enquanto que o que se tinha em vista era alcançar o progresso e a civilização. Tal questionamento acabou levando a uma identificação do brasileiro pela ausência do que se esperava ele pudesse ser, ou seja, por aquilo que the faltava." 65

Para isso, a C.P.R.Pr., faz tabula rasa sobre as medidas profiláticas desenvolvidas pela cultura indígena, do trabalho desde a infância, da existência de uma medicina popular e do crescimento agrícola. A vida dos trabalhadores no campo é vista como o negativo, o avesso da civilização desejada, seus conhecimentos e seu trabalho é desprezado. São representados como ignorantes e embrutecidos, às vezes por ignorância e sempre pela doença. Vistos como seres incapazes de autogestão, necessitando serem retirados de uma situação de falta, de ausência, por uma nomos planificada por um sujeito do conhecimento externo a eles.

A modernidade é fiel a herança metafísica ocidental e com isso ao politizar a vida nua e incluí-la na polis, o faz construindo a política como biopolítica. ${ }^{66}$ Assim, a zoé, a vida nua, entra na polis e o viver é transformado em bem viver, entendido como o viver de um corpo disciplinado, mas ainda excluído. Pois que a inclusão ocorre apenas diante do abandono de sua vontade autônoma em nome de uma submissão aos objetivos pragmáticos de um outro.

O projeto de construção de um povo para o Brasil estado-nação pretendeu incluir trabalhadores rurais tutelados, vistos como sem ilustração em permanente minoridade. Lembrando Kant:

O esclarecimento é a saída do homem de sua menoridade, da qual ele próprio é culpado. A menoridade é a incapacidade de fazer uso de seu entendimento sem a direção de outro indivíduo. [...] A preguiça e a covardia são as causas pelas quais

\footnotetext{
${ }^{63}$ Ver: AGAMBEN, Giorgio. Homo sacer: O poder soberano e a vida nua. 2ed. Belo Horizonte: UFMG, 2010.

${ }^{64}$ SOUZA ARAUJO. Profilaxia..., op. cit, p. 211.

${ }^{65}$ NAXARA, M. Estrangeiro em sua própria terra..., op. cit., p. 18.

${ }^{66}$ AGAMBEM, G. Homo Sacer..., p. 15.
} 
uma tão grande parte dos homens, depois que a natureza de há muito os libertou de uma direção estranha, continuem no entanto de bom grado menores por toda a vida. São também as causas que explicam por que é tão fácil que os outros se constituam em tutores deles. É tão cômodo ser menor ${ }^{67}$.

O vivente rural era transformado em sinônimo de atraso, sozinho não teria futuro, só os médicos a esse conheciam, mas ser o oráculo é também um papel na tragédia. $A$ comissão de Profilaxia sustentava então uma minoridade de longa duração para essas populações, tuteladas por seus senhores, sejam eles senhores de terras, de saberes ou soberanos.

A pesquisadora Carmem Kummer também apontou, com muita propriedade, ao final de sua dissertação dedicada a Profilaxia Rural no Paraná, uma permanência do problema da saúde nas zonas rurais do estado, assim:

Conforme o IPARDES, apenas 35,8\% de 199 municípios considerados rurais apresentavam (em 2001) algum tipo efetivo de prestação de serviços na área da saúde. Não podemos negar que nenhuma ação foi tomada desde a década de 1910, uma vez que o saneamento no meio rural nessa época deu início a muitos projetos realizados décadas depois. Por outro lado, possivelmente podemos afirmar que as justificativas apresentadas para definir este índice alarmante se inserem nas mesmas queixas apresentadas por Souza Araújo, João de Barros Barreto e Eduardo Leal Ferreira, quais sejam, o infindável descaso político das elites locais com aqueles que julgam ser irrelevantes e desnecessários para o país. ${ }^{68}$

Uma continuidade de problemas que poderiam ser trazidos para a ordem do dia sob as mesmas justificativas utilizada pelos médicos do início do século XX. Ou seja, uma permanência de uma visão de mundo em torno do rural e sobre as pessoas que lá vivem.

Essas permanências se caracterizam como um conjunto de estigmas, metáforas, estratégias, imagens, políticas, etc; dispostas para o rural e que partem do pressuposto de uma eterna minoridade daquela população. Consequentemente, o apelo recorrente é por formas de tutela e conseguinte sujeição, como uma inferioridade diante do urbano, do moderno, do científico e do erudito. Não seria a toa que os discursos sobre a modernidade no campo hoje, início do século XXI, sejam ligados ao agronegócio, um empreendimento extremamente mecanizado e de alta tecnologia, que necessita de poucos viventes no campo. Sem os viventes, só restaria a terra boa? Por outro lado, a agricultura familiar é objeto de inúmeras tentativas de resgate, de conservação, ou ainda de criação de opções econômicas sustentáveis, as quais permitam a sua sobrevivência. Propostas cientificamente embasadas por bem intencionados saberes acadêmicos.

Aqui, novamente a heteronomia, as soluções encontradas para os problemas criados, são elaborados por outrem com interesses e disposições de fora da vontade autônoma. As pessoas envolvidas e as necessidades por elas mesmas percebidas, não

\footnotetext{
${ }^{67}$ KANT, I. O que é esclarecimento? Op. cit.

${ }^{68}$ KUMMER, Carmem Sílvia da F. Não esmorecer para não desmerecer: As práticas médicas sobre saúde da população rural paranaense na primeira república. Dissertação (Mestrado em História) Curitiba: UFPR, 2007, p. 136.
} 
participam do projeto, esvaziando a ação como um processo autônomo de responsabilização. Em ambos os casos, a verdade científica incorre, mais uma vez, no perigo de subsumir o outro. Lembrando mais uma vez Foucault "vocês não tem direito de menosprezar o presente." ${ }^{\prime 69}$ Pois cada um é responsável pelo processo histórico do conjunto. Afinal a modernidade é uma atitude, uma maneira de pensar e agir que se apresenta como tarefa.

\section{CONSIDERAÇÕES}

Em 1919 a Profilaxia Rural no Paraná propunha questões mais amplas do que o saneamento do sertão paranaense, pois que era a vida das pessoas o objeto de intervenção. O rural era visto pela Profilaxia como um espaço de falta, o olhar que se lançava não via o que lá existia, pois o quanto prostrado pela doença e indolente pelos vermes podia ser um trabalhador que sustentavam a economia do estado?

No Relatório da C.P.R.Pr. não faltam exemplos disso, porém sempre citados de forma indireta. Como quando o médico analisa a Doença de Soduku, decorrente da mordida de rato e narra as condições de vida da menina que fora mordida. Ela tinha 11 anos e trabalhava de empregada doméstica na casa de um advogado em Curitiba a onde fora mordida. Sua família era de 'origem polaca' e continuava morando em Ponta Grossa, onde eram agricultores. ${ }^{70}$ Também a vida dos homens moradores do Alto e Baixo Paraná descritos como ausentes por estarem trabalhando na coleta e transporte do mate. Eram homens, mulheres e crianças, todos sujeitos de sua própria sobrevivência cotidiana, porém narrados como objetos de intervenção.

E os outros saberes? Souza Araujo transcreveu o relatório de Álvaro Lobo sobre Tomazina: "Não só a gripe vitimou enormemente a população sertaneja, também os curandeiros e raizeiros, bem como práticas de farmácia audaciosos e incompetentes aumentaram extraordinariamente o coeficiente de mortalidade, chegando a tal imbecilidade muita vez às raias do assassínio puro e frio." ${ }^{71}$ Os saberes saneadores populares são assim ou culpabilizados pela piora do caos higiênico já existente, como no caso da Gripe, ou silenciados. Contra esse silêncio pode-se recordar a fala sobre Foz do Iguaçu como um local de total caos na visão do médico, mas que por outros documentos pode-se saber que ali residia a senhora Joana Rosa, descrita como alguém de grande conhecimentos sanadores, inclusive salvando a vida de militares alocados na Colônia Militar de Foz. ${ }^{72}$ Também as formas indígenas de profilaxia das doenças, descritas no relatório, mas não consideradas como tal. Nesses pequenos fragmentos da vida dos outros, a heteronomia das populações rurais se dissolve, transforma-se em uma ilusão de ótica, talvez uma farsa. De longa

69 FOUCAULT, M. O que são as luzes? In: Arqueologia das Ciências e História dos sistemas de pensamento. (Ditos e Escritos II) 2 ed. Rio de Janeiro: Forense universitária, 2005, p. 341- 349.

${ }^{70}$ SOUZA ARAUJO. Profilaxia..., p. 314.

${ }^{71}$ Idem, p. 125-126.

${ }^{72}$ Ver novamente: MYSKIW, Antonio Marcos. A Fronteira como Destino de Viagem: A Colônia Militar de Foz do Iguassu. Tese (Doutorado em História). Niterói: UFF, 2009. 
permanência, mas ainda uma farsa.

É para encontrar caminhos para essa proposta que se reflete mais uma vez sobre a Profilaxia Rural. Essa, como um dispositivo de conhecimento, constituiu bem intencionados procedimentos produtores de novos sujeitos, mas foi também um projeto de heteronomia. Eis a sua tragédia, querer dessujeitar o outro em nome de uma nova sujeição, mas produzir apenas sujeitos espectrais. Retornando a Giorgio Agamben, os viventes encontram os dispositivos entendendo-se esses como: "Qualquer coisa que tenha de algum modo a capacidade de capturar, orientar, determinar, interceptar, modelar, controlar e assegurar os gestos, as condutas, as opiniões e os discursos dos seres viventes." ${ }^{73}$

Se a vida e as pessoas envolvidas no projeto profilático são compostas como sujeitos espectrais e os próprios processos de subjetivação eram essenciais para a construção de possibilidades de integração política, a própria motivação primeira da intervenção profilática, a saber, a invenção de um estado-nação, teria como resultado apenas sujeitos fantasmas e, assim, o palco político composto permanecerá vazio.

Seguindo as reflexões de Foucault e Agamben, por uma última vez, o dispositivo atende a uma urgência, apresenta-se como estratégia concreta de saberes e poderes ${ }^{74}$. A Profilaxia Rural será um dispositivo não só pela sua urgência (após a construção do rural como um problema nacional pelos próprios médicos), mas também pelos seus procedimentos para a gestão prática dos viventes. Pois ela, através de sua geografia médica, dispôs, ao organizar as normas de conduta do viver; situou, ao construir as regiões endêmicas e, também, positivou, isto é, coagiu, comandou sentimentos e comportamentos.

É nesse sentido que a Profilaxia dessujeitava os viventes ao reproduzir a heteronomia e constituí-los como incapazes de autonomia. Assim, o agricultor higiênico, ou o Paraná saneado, bem como, o médico ilustrado e o guarda sanitário obediente, são visagens de um olhar iludido, capturado por promessas de felicidade e de possibilidades de evitar a dor através da intervenção da razão, de sua técnica e ciência.

Nem a ação da Profilaxia Rural atingiu os seus objetivos, nem a zoé foi incorporada definitivamente a polis. O bem viver continuou o viver. Projetos grandiloquentes no Brasil do século XX tendiam a ser aplicados apenas de maneira fragmentária e particularista, quando não clientelista. O trágico subjacente em todo conhecer se mantinha. $O$ indizível, o imprevisível, o inclassificável permanece na complexidade da vida cotidiana.

Recebido em 05/08/2012

Aceito para publicação em 01/10/2012

\footnotetext{
${ }^{73}$ AGAMBEM. O que é o contemporâneo? Op. cit., p. 40.

${ }^{74}$ AGAMBEM, op. cit., p. 29.
} 